\title{
Dapsone syndrome occurring in two brothers
}

\author{
K JAMROZIK \\ Unit of Clinical Epidemiology, University of Western Australia, $M$ \\ Block, Queen Elizabeth II Medical Centre, Nedlands 6009, Western \\ Australia
}

Accepted for publication 10 July 1985

\begin{abstract}
Summary Two cases of dapsone syndrome occurring in brothers under treatment for multibacillary leprosy in Papua New Guinea are described. Both patients had rash, fever and jaundice, together with signs suggestive of chest infection. One patient died after developing a haemorrhagic diathesis, but the other improved rapidly after therapy with corticosteroids was commenced. Previous case reports of dapsone syndrome are reviewed.
\end{abstract}

\section{Introduction}

Dapsone (diamino-diphenyl sulphone) was first synthesized in 1908, but its antibacterial properties remained undiscovered until $1937 .{ }^{1}$ Since the early $1940 \mathrm{~s}$ it has been used in the treatment of a very wide variety of conditions, ${ }^{2-4}$ but its chief importance has been in the treatment of leprosy. In 1949, it was reported that dapsone therapy precipitated an infectious-mononucleosis-like syndrome in $12 \%$ of a series of 305 Nigerian leprosy patients within 2-5 weeks of commencement of the drug. ${ }^{5}$ A further 3 cases of 'dapsone syndrome' ${ }^{6}$ were described in $1951,{ }^{7}$ but it should be noted that very large doses of dapsone were being prescribed in those early years, in the region of $300 \mathrm{mg} / \mathrm{day}$. The fact that few additional cases have been reported since then, despite the millions of leprosy sufferers receiving the drug, is probably related to the lower dosages used, and justifies the conclusion that the syndrome is a rare complication of dapsone therapy. I describe the occurrence of this syndrome in two brothers prescribed dapsone for the treatment of leprosy.

\section{Case 1}

A 20-year-old Melanesian man was referred to Port Moresby General Hospital, Papua New Guinea, from a rural health centre in August 1983 with a suspected 
dapsone reaction. Dapsone $100 \mathrm{mg}$ /day plus clofazimine $100 \mathrm{mg}$ /day had been commenced for multibacillary leprosy approximately 6 weeks previously, but the dapsone had been stopped 2 days prior to admission after he had developed a rash.

On admission, on 18 August, he was a well-built young man who had a morbilliform rash over the trunk and limbs, and looked unwell. He had a fever, his sclera were jaundiced, and there was tender hepatomegaly but no splenomegaly. His lips were cracked and dry, but there was no evidence of submucosal or subcutaneous haemorrhage. He had a dry cough.

Investigations showed serum bilirubin (SBR) $96 \mu \mathrm{mol} / 1$, (normal $<17$ ) with direct bilirubin $63 \mu \mathrm{mol} / \mathrm{l}$, SGOT 83 and SGPT 100 (normal for both $<40 \mathrm{IU} / 1$ ), serum creatinine $141 \mu \mathrm{mol} / 1$ (normal $<125 \mu \mathrm{mol} / 1$ ) and blood urea $5.5 \mathrm{mmol} / 1$ (normal 3-8 mmol/l). A chest X-ray was normal, and a blood culture grew a micrococcus regarded as a contaminant. A working diagnosis of severe dapsone reaction was made and all drugs were stopped.

Repeat biochemistry one week later showed normal serum electrolyte levels with urea $14.8 \mathrm{mmol} / \mathrm{l}$, creatinine $159 \mu \mathrm{mol} / \mathrm{l}$, SBR $180 \mu \mathrm{mol} / \mathrm{l}$ (direct bilirubin 154) and SGPT $170 \mathrm{IU} / 1$. Haematological findings were $\mathrm{Hb} 109 \mathrm{~g} / \mathrm{l}$, total WCC $5.3 \times 10^{9} / 1(\mathrm{~N} 64 \%, \mathrm{~L} 25 \%, \mathrm{E} 1 \%, \mathrm{M} 10 \%)$ and normal platelets.

Over the next 2 weeks fever and chest signs prompted treatment with intravenous ampicillin and an orciprenaline inhaler, and his general condition improved. Reassessment on 13 September (day 26) showed Hb 107 g/l, WCC $6 \cdot 5 \times 10^{9} / 1(\mathrm{~N} 66, \mathrm{~L} 29, \mathrm{E} 4, \mathrm{M} 1$ ) and normal platelets; urea $6.0 \mathrm{mmol} / 1$, creatinine $97 \mu \mathrm{mol} / 1$, SBR $70 \mu \mathrm{mol} / 1$, SGOT 170, alkaline phosphatase 160 (normal $<100$ IU/1).

Six days later he complained of nose bleeds, mouth ulcers and joint pains. Examination showed a temperature of $36 \cdot 5^{\circ} \mathrm{C}$, signs of shock, and a respiratory rate of 40 . The sclera were still jaundiced, there was frank epistaxis, plus mouth ulcers and cracks in the skin of both elbows. Haemoglobin was now $92 \mathrm{~g} / \mathrm{l}$, WCC $13 \cdot 3 \times 10^{9} / 1(\mathrm{~N} 73, \mathrm{~L} 16, \mathrm{E} 1, \mathrm{M} 10)$ and platelets were 'markedly decreased'. The picture was thought to represent septicaemic shock secondary to chest infection. Blood pressure rose to $110 / 70 \mathrm{mmHg}$ after a rapid infusion of Haemaccel. Supplemental oxygen was given. Ampicillin was continued, and gentamicin commenced. Supportive care included Gastrogel tablets, thymol mouth washes and nystatin drops, and antiseptic cream and lotion to the skin cracks.

Blood pressure fell overnight to $70 / 50 \mathrm{mmHg}$ but again responded to a rapid infusion of fluid. The next day epistaxis continued and was now accompanied by frank haemoptysis. The respiratory rate had fallen to $22, \mathrm{Hb}$ to $63 \mathrm{~g} / \mathrm{l}$, with WCC $15.0 \times 10^{9} / 1(\mathrm{~N} 80)$ and platelets $10 \cdot 0 \times 10^{9} / 1$. Biochemistry showed $\mathrm{Na}^{+} 128 \mathrm{mEq} /$ 1, urea $18.5 \mathrm{mmol} / 1$, creatinine $97 \mu \mathrm{mol} / 1$, SBR $185 \mu \mathrm{mol} / 1$, SGOT 215, alkaline phosphatase 174. He was transfused with 2 units of packed red cells, but his general condition remained unchanged.

The following day (day 34) he was transfused with 2 units of fresh frozen 
plasma, and ampicillin was discontinued in favour of intravenous crystalline penicillin, as the respiratory rate had risen to 44 , and it was felt that the picture was one of a life-threatening pneumonia, possibly pneumococcal. Blood culture, reported later, grew a bacillus species, regarded as a contaminant. That evening, he was observed to be restless, and again found to be shocked. He then had a respiratory arrest and could not be resuscitated.

\section{Case 2}

Some 4 months later, in January 1984, the brother of Case 1 was referred from the same health centre with a suspected dapsone reaction. Dapsone and clofazimine (100 mg/day of each) had been started on 13 December 1983 for the treatment of leprosy lesions which had been present for 18 months. He had developed a rash on the 8 January, 5 days prior to admission.

On admission, he was a well-built, 20-year-old man with an erythematous maculopapular rash involving the trunk, face and limbs, together with a red nodular lesion, $4 \mathrm{~cm}$ in diameter, in the left prepatellar area, and a further $10 \mathrm{~cm}$ 'island' lesion with satellite nodules on the upper lateral thigh. There were large hypopigmented, non-anaesthetic macules on the right upper arm and posterior aspect of the left thigh. He was not jaundiced, the oral mucosa was normal, and there was lymphadenopathy in the neck and axillae. There was no weakness, but an early left ulnar claw was present, and there was anaesthesia to light touch in the left ulnar fingers, left lateral leg, and medial right foot. He gave a one-week history of epigastric discomf ort made worse by food and relieved by defaecation. There was no history of cough, haemoptysis or haematemesis, no fever, and the chest and abdomen were normal on examination. A diagnosis of borderline (BB) leprosy with drug reaction was made, and all drugs were stopped. Investigations included skin smear (Bacteriological Index 4.0, Morphological Index $12 \%$ in one of the lesions), and routine laboratory tests- $\mathrm{Hb} 124 \mathrm{~g} / \mathrm{l}$, WCC $10 \cdot 0 \times 10^{9} / 1(\mathrm{~N} 72$, L 16, E 4, M 8), alkaline phosphatase 126, SGOT 66; SBR, urea, creatinine and serum electrolytes were not estimated.

By day 3 the rash was fading, revealing large hypopigmented macules over the whole trunk. He developed a fever, and examination showed slight jaundice, $3 \mathrm{~cm}$ tender hepatomegaly, lymphadenopathy as previously noted, but no splenomegaly.

On day 6 the temperature had risen to $39^{\circ} \mathrm{C}$, he had two episodes of vomiting and diarrhoea, and still complained of epigastric pain. The rash appeared worse, probably due to erythema associated with the fever, but the physical findings were unchanged. Investigations showed $\mathrm{Hb} 121 \mathrm{~g} / \mathrm{l}$, WCC $16 \cdot 0 \times 10^{9} / 1$ (N 35, L 28, E 24 , M 2, Band cells 6, and atypical lymphocytes 5, with increased toxic changes in the neutrophils relative to those present at admission). Blood culture and hepatitis B screen were negative. 
The next day the rash was unchanged, fever persisted, and he had developed a moist cough. Examination showed him to be frankly jaundiced, with 7-8 cm tender hepatomegaly, no splenomegaly and lymphadenopathy unchanged. Breath sounds were equal but bronchial with fine expiratory rhonchi in all zones. A chest X-ray was normal. His parents were requesting that he be allowed weekend leave to consult a traditional healer, but they were persuaded that he should remain in hospital. Prednisolone $40 \mathrm{mg} /$ day was commenced.

Two days later (day 9) he was afebrile and feeling and looking better. The rash was beginning to resolve, as was the lymphadenopathy, but he still had a moist cough. There was 6-cm hepatomegaly, but it was only slightly tender. The breath sounds were no longer bronchial, although scattered fine rhonchi were still heard. SBR was $233 \mu \mathrm{mol} / 1$ (direct bilirubin 168), SGOT 300, alkaline phosphatase 62 .

Over the next week he improved steadily. The chest became normal to clinical examination, the jaundice faded, and the lymphadenopathy and hepatomegaly gradually resolved. The rash faded completely, but desquamation began on day 11.

The prednisolone dose was reduced to $30 \mathrm{mg} /$ day over the next 2 weeks and he was discharged on day 35 . He was then seen weekly in out-patients and remained well, on a reducing dose of steroid. On 7 March (day 53), $\mathrm{Hb}$ was $130 \mathrm{~g} / \mathrm{l}$, WCC $8 \cdot 1 \times 10^{9} / 1$ with $6 \%$ monocytes and $1 \%$ atypical lymphocytes still present. Liver function tests were normal.

\section{Comment}

Although it was not possible to carry out a full screen for infectious, particularly viral, diseases, these 2 cases are typical of the 'dapsone syndrome'. ${ }^{6}$ Each patient was taking clofazimine at the time his illness began, but this clinical picture has not been described as a complication of therapy with that drug, and the second case later resumed taking clofazimine regularly, without adverse effect.

A morbilliform rash developing approximately 5 weeks after the inception of dapsone therapy is such a common complication as to be known as 'dapsone dermatitis', ${ }^{8}$ but the full 'dapsone syndrome' appears to have a much lower incidence. ${ }^{3,}{ }^{9-11}$ Indeed, although one study ${ }^{12}$ has reported the development of a typical rash in $4.6 \%$ of a series of 108 new cases of leprosy treated with dapsone in Port Moresby, only 20 cases of the 'dapsone syndrome' appear to have been reported in the literature $2,4,6,7,9,10,13-16$ in the 35 years following the original description. ${ }^{5}$ Those authors ascribed the condition to the exacerbation of an existing but sub-clinical infection with infectious mononucleosis, on the basis of persisting lymphocytosis and high Paul-Bunnell titres. Indeed, in view of the rarity of subsequent case reports, the high incidence originally reported ${ }^{5}$ might suggest an infectious illness. Later reports consider that the syndrome is due to an idiosyncratic hypersensitivity reaction to dapsone. ${ }^{1,4,6,9}$ 
Eight of the 20 patients reported since 1949 received dapsone for conditions other than leprosy, and, including the 2 present cases, only $36 \%$ developed the complete clinical complex of rash, fever, jaundice and lymphadenopathy, which is in keeping with the observation of one study ${ }^{16}$ that the full syndrome is rare. Where it occurred, fever was generally high and lasted for one week or more. Characteristically the jaundice and hepatomegaly took even longer to resolve. Steroids were given in 7 cases, but were associated with a rapid resolution of fever in only 3 of these.

The first case reported here is only the fourth death from the 'dapsone syndrome' recorded, but an overall case fatality rate of $19 \%$ is not inconsiderable, even though there may be a tendency for more serious cases to be reported. Two of the fatal cases had falling platelet counts accompanied by pulmonary haemorrhage in the terminal phases. In one reported case ${ }^{10}$, the platelet count fell 'without evidence of disseminated intravascular coagulation', but the appropriate laboratory tests to rule out disseminated intravascular coagulation were not performed in the first of the present cases.

The occurrence of the syndrome in siblings has not previously been reported but, in view of the apparent rarity of the condition, supports the suggestion ${ }^{15}$ that it occurs in individuals with a genetic predisposition.

\section{Acknowledgments}

Professor I Riley kindly drew my attention to several of the references, and he, Professor S Naraqi and Dr A Saweri were the consultants involved in the management of the 2 cases. Drs J Schneider and J Potter provided comments on the manuscript.

\section{References}

${ }^{1}$ Lowe J. Treatment of leprosy with diamino-diphenyl sulphone by mouth. Lancet, 1950; i: 14550.

2 Millikan LE, Harrell ER. Drug reactions to the sulphones. Arch Dermatol, 1970; 102: 220-4.

${ }^{3}$ Graham WR. Adverse effects of dapsone. Int J Dermatol, 1975; 14: 494-500.

${ }^{4}$ Tomecki KJ, Catala CJ. Dapsone hypersensitivity, the sulphone syndrome revisited. Arch Dermatol, 1981; 117: 38-9.

${ }^{5}$ Lowe J, Smith M. The chemotherapy of leprosy in Nigeria. Int J Lepr, 1949; 17: 181-95.

6 Allday EJ, Barnes J. Toxic effects of diaminodiphenylsulphone in treatment of leprosy. Lancet, 1951; ii: 205-6.

7 Jelliffe DB. Toxic hepatitis caused by diaminodiphenylsulphone. Lancet, 1951; i: 1343-4.

${ }^{8}$ Browne SG. Desensitization for dapsone dermatitis. Br Med J, 1963; ii 664-6.

9 Leiker DL. The mononucleosis syndrome in leprosy patients treated with sulphones. Int J Lepr, 1956; 24: 402-5. 
${ }^{10}$ Frey HM, Gershon AA, Borkowsky W, Bullock WE. Fatal reaction to dapsone during treatment of leprosy. Ann Intern Med, 1981; 94: 777-9.

11 Anonymous. Adverse reactions to dapsone. Lancet, 1981; ii: 184-5.

12 Ree GH, Kame P. Skin reactions to dapsone. Papua New Guinea Med J, 1981; 24: 57-8.

${ }^{13}$ Potter B, Szymanski FJ, Fretzin D. Erythema elevatum diutinum and sulphone hypersensitivity. Arch Dermatol, 1967; 95: 436-40.

${ }^{14}$ Lal S, Garg BR. Sulphone induced exfoliative dermatitis and hepatitis. Lepr India, 1980; 52: 3025.

15 Gan TE, Van der Wyden MB. Dapsone-induced inf ectious mononucleosis-like syndrome. Med J Aust, 1982; i: 350-1.

16 Kromann NP, Vilhelmsen R, Stahl D. The dapsone syndrome. Arch Dermatol, 1982; 118: 531-2. 